\title{
Endüstri 5.0 (Toplum 5.0) ve Mimarlık
}

\author{
Elif Gizem Yetkin ${ }^{1 *}$, Kemal Coşkun ${ }^{2}$ \\ 1* Alanya Hamdullah Emin Paşa Üniversitesi, Mimarlık Fakültesi, Antalya, Türkiye, (ORCID: 0000-0001-8775-8313), gizemtelli@gmail.com \\ 2 Alanya Hamdullah Emin Paşa Üniversitesi, İktisadi ve İdari Bilimler Fakültesi, Antalya, Türkiye (ORCID: 0000-0003-2631-7543), kemalcsknn@gmail.com
}

(İlk Geliş Tarihi 11 Temmuz 2021 ve Kabul Tarihi 9 Eylül 2021)

(DOI: $10.31590 /$ ejosat.969631)

ATIF/REFERENCE: Yetkin, E. G. \& Coşkun, K. (2021). Endüstri 5.0 (Toplum 5.0) ve Mimarlık. Avrupa Bilim ve Teknoloji Dergisi, (27), 347-353.

\section{Öz}

Endüstri devrimleri içinde bulundukları dönem ve dönemin şartlarına göre çok önemli birer dönüşüm süreci olmuşlardır. Bu süreçler yalnızca endüstri alanında değil beraberindeki birçok disiplin ve alanda değişim getirmiştir. Bu gelişmelere paralel olarak insanların yaşam biçimleri, alışkanlıkları ve çalışma standartları da farklılaşmıştır. Birinci sanayi devrimi ile birlikte üretim safhasında yer alan kas gücüne su ve buhar gücünün kullanımı eklenmiş, elektriğin keşfi ile birlikte ikinci sanayi devriminde seri üretim yöntemi yaşamımıza dahil olmuştur. Bilgisayarlar, üçüncü sanayi devrimi dönüşüm döneminde teknolojide yaşanan gelişmeler neticesinde günlük yaşamımıza ve üretim sürecine girmiştir. Dördüncü sanayi devrimi de ürün ve hizmetlerin hızlı, toplu ve sistematik bir şekilde üretilmesi için teknolojiyi üretim safhasına entegre eden bir dönüşüm süreci olmuştur. Son olarak ise üretim safhasına entegre olan teknolojinin toplum için bir tehdit unsuru olarak değil de tam tersi topluma yardımcı bir unsur olarak değerlendirilmesi gerektiğini temeline dayanan beşinci sanayi devrimi, diğer bir ifadeyle Endüstri 5.0 (Toplum 5.0) yaşamımıza girmiştir. Bu yeni dönüşüm sürecinin de ilk dört endüstri devriminin çeşitli disiplin ve alanlardaki etkileri gibi birtakım etkileri vardır. Bu çalışmada öncelikle ilk dört sanayi devriminin Mimarlık alanındaki etkileri incelenerek endüstriyel devrim sürecinin son aşaması olan Endüstri 5.0’ın Mimarlık alanındaki mevcut ve potansiyel etkilerinin tespit edilmesi amaçlanmaktadır.

Anahtar Kelimeler: Endüstri Devrimleri, Endüstri 5.0, Toplum 5.0, Mimarlık.

\section{Industry 5.0 (Society 5.0) ve Architecture}

\begin{abstract}
Industrial revolutions have been a very important transformation process according to the period and the conditions of the period. These processes have brought changes not only in the industry but also in many disciplines and fields. Parallel to these developments, people's lifestyles, habits and working standards have also changed. With the first industrial revolution, the use of water and steam was added to the muscle power in the production phase, and with the discovery of electricity, mass production methods were included in our lives in the second industrial revolution. Computers have entered our daily life and production process as a result of the developments in technology during the transformation period of the third industrial revolution. The fourth industrial revolution is a transformation process that integrates technology into the production phase for the rapid, collective and systematic production of products and services. Finally, the fifth industrial revolution in other words Industry 5.0 (Society 5.0) which is based on the fact that the technology integrated into the production phase should not be considered as a threat to the society but as a helpful element to the society has entered our lives. This new transformation process has some effects like the effects of the first four industrial revolutions in various disciplines and fields. In this study, it is aimed to determine the current and potential effects of Industry 5.0 which is the last stage of the industrial revolution process in the field of Architecture by examining the effects of the first four industrial revolutions in the field of Architecture.
\end{abstract}

Keywords: Industrial Revolutions, Industry 5.0, Society 5.0, Architecture.

*Sorumlu Yazar: gizemtelli@gmail.com 


\section{Giriş}

Tüm toplumlarda, tüm disiplinlerde hatta daha geniş bir çerçeveden bakmak gerekirse yaşamımızda yer alan bütün konularda bir değişim ve gelişim olduğu açıktır. Bu farklılaşma ve ilerleme sürecinde yer alan en önemli alanlardan birisi de endüstridir. Endüstri, bir ülkenin veya bir toplumun eğitim seviyesi, gelişmişlik düzeyi, üretim ve tüketim seviyeleri gibi birçok göstergesi hakkında fikir verir. Endüstri gücü ve kapasitesi ile endüstri gelişimine olan adaptasyon hızı yüksek olan toplumlar aynı doğrultuda farklı disiplin ve alanlarda da gelişme gösterir.

Değişim ve gelişim özünde ihtiyaçların karşılanma arzusundan buna bağlı olarak da beğeni ve taleplerin değişmesinden kaynaklanır. Endüstri de bu hareketlilik karşısında çağın bir gerekliliği olarak kendisini geliştirmiştir. Bu hareketlilik sürecinde toplumunun refahı, huzuru ve mutluluğunu sağlamakta görevli olan devletler, buluş ve fikirleriyle insanlığa katkıda bulunmaya çalışan bilim insanları ile toplum ihtiyaçlarını karşılayacak olan mal veya hizmetleri üretmek amaciyla iktisadi bir girişimde bulunan kurum ve kuruluşlar sürecin aktörleri arasında yer almaktadır. İlerleyen süreçte dünya nüfusunda yaşanan artış buna bağlı olarak üretim ve tüketimin artması, teknoloji alanında yaşanan gelişmeler her alanı etkilemiştir. Ekonomi, finans, işletme, hukuk, sağlık, sosyoloji, mühendislik, mimarlık vb. gibi alanlar bu süreçte etkilenen önde gelen alanlar arasında yer almaktadır. Bu alanlar, dönemin şartlarına göre belirli formlara kavuşarak her geçen gün sahip oldukları bilgi birikimlerini arttırmıştır.

$\mathrm{Bu}$ çalışmada da öncelikle endüstrinin tarihsel gelişimi incelenerek, mimarlık alanındaki etkilere yer verilmiştir. Daha sonra henüz yeni bir kavram olan ve odağında toplum olan Endüstri 5.0, diğer bir ifade ile Toplum 5.0 değerlendirilmiştir. Son olarak ise bu yeni kavramın mimarlık alanında hangi konumda olduğu ile bu alandaki mevcut ve potansiyel etkileri ele alınmıştır.

\section{Endüstri Devrimleri Tarihi}

Milattan önceki y1llarda toprak ana sermaye unsurudur. Bu dönemlerde tarım ile yaşamlarını idame ettiren toplumlar uzun yıllar boyunca üretimlerini kas gücüyle ve işlerini bir miktar daha kolaylaştırabilmek adına geliştirdikleri aletlerle yapmışlardır. $\mathrm{Bu}$ devirlerde yaşayan insanların ana sermaye unsurları ve iş güçleri başlıca üretim aracı olarak değerlendirilmektedir. Uzun yıllar boyunca süregelen bu durum, teknoloji ve bilgi birikimin de artmasıyla birlikte üretimin fabrikalara taşınmasını sağlamıştır. Sanayi devrimi olarak da adlandırılan bu dönüşüm insan hayatının bütün alanlarında yeni bir düzenlemeye ortam hazırlamıştır (Günay, 2002).

Endüstri 1.0 veya daha yaygın kullanımı ile birinci sanayi devrimi İngiltere'de başlamıştır ve bu devrim iki aşamada değerlendirilmektedir. Birincisi bu devrime konu olan icatların ortaya çıkışı ile bu icatların kullanımının ilk yıllarıdır. İkincisi ise bu yararlı ve yeni teknolojilerin İngiltere'den diğer ülkelere taşınma safhasıdır. İngiltere'de bolca bulunan ve tam tersi bir şekilde bölgede bulunmayan veya kıt olan kaynaklar için birtakım çalışmalar yapılmıştır. Bu çalışmaların sonucunda su ve buharın kullanımı gibi yeni girişimler birçok fabrikada uygun maliyetli üretime ortam hazırlamıştır (Allen, 2009).

e-ISSN: 2148-2683
Üretim ve sermayede yaşanan artış diğer ülkelerle etkileşimi arttırmış ve yaşanan bu dönüşümün diğer ülkelere de sıçramasına neden olmuştur. Avrupa ve Amerika gibi kıtalara da sıçrayan bu yenilik, bölgelerde sermaye ve bilgi birikimlerinde de artış getirmiştir.

Endüstri 2.0 veya bazı kaynaklarda Teknoloji Devrimi olarak da adlandırılan ikinci sanayi devriminin temelinde daha önce basit mekanik sistemlerle yapılan üretimin ihtiyaç duyduğu enerjiyi elektrikten almaya başlaması yatmaktadır. Jovens (1931), Amerika'da 1865-1896 ve Avrupa'da 1983-1894 yılları arasında fiyatlarda yaşanan büyük düşüşlerin, üreticilerin maliyetleri düşürme noktasında çok fazla mesai harcamalarına neden olduğunu belirtmiştir. Bu çalışmaların sonucunda bir ürün ya da bir ürün grubunun aynı anda yüzlerce ya da binlerce sayıda arka arkaya üretilmesi esasına dayanan seri üretim yönteminin Amerika'da bulunması düşen fiyatlar karşısında oldukça başarılı bir çözüm olarak değerlendirilmiştir. Pamuk, kağıt, gıda, saat gibi ürün ve ürün gruplarında kullanılan yeni üretim yöntemi zamanla daha da yaygınlaşarak sürekli bir üretim yöntemi haline gelmiştir.

Birinci ve ikinci sanayi devrimi birçok yönden farklı olsa da her biri endüstri alanında üretim süreçlerini temelden değiştirecek farklı yeni teknolojiler üzerine inşa edilmiştir. Ayrıca bu yeni teknolojilerin benimsenmesi, üreticilerin üretim hacimlerini arttırmasına olanak sağlamıştır. Yaşanan bu hacim artışı da topluma daha yüksek yaşam standartları sağlamıştır. Endüstri 3.0 veya diğer bir ifade ile üçüncü sanayi devrimine gelindiğinde dönüşümün merkezinde internet yer almaktadır. İnsanların birbirleriyle iletişim kurma, kendilerini ifade etme ve eğlence biçimlerini dahi etkileyen internet, şirketlerin ve bireylerin çalışma biçimlerini yeniden şekillendirmiştir (Smith, 2001). Bu dönüşümün merkezinde yer alan internetin yanında, teknolojinin ve haberleşme olanaklarının gelişmesi, mevcut enerji kaynaklarının bir sınırı olduğunun fark edilmesiyle yenilenebilir enerji kaynaklarına gösterilen ilginin artması ve bilgisayarların sektörlere dahil olması gibi birçok gelişme yer almaktadır. 20. yüzyılın ikinci çeyreğinde geliştirilen çeşitli algılayıcılardan aldığı bilgiyi kendisine tanımlanan programa göre işleyen ve elde ettiği bulguları aktaran mikroişlemciler sanayi sektöründe yeni bir dönem başlatmıştır. Bu yeni dönem, insan ve makinelerin üretim sürecini paylaşmalarını ve üretimin sayısallaşmasını sağlamıştır.

Endüstri 4.0 kavramı, ilk kez Alman hükümeti tarafindan Kasım 2011'de ileri teknoloji stratejisi olarak yayımlanan bir makalede görülmüştür. Nisan 2013'te Almanya'nın Hannover kentinde gerçekleşen bir sanayi fuarında tekrar adından söz ettiren Endüstri 4.0 geniş çapta bir ilgi uyandırmıştır ve birçok sektör için takip edilmesi gereken bir konu haline gelmiştir (Zhou, Lio \& Zhou, 2015). Schwab (2020), Endüstri 4.0'1 veya diğer bir ifade ile dördüncü sanayi devrimini, üçüncü sanayi devrimi üzerine inşa edilen, bünyesinde hız, kapsam ve sistem etkisi unsurlarını barındıran bir dönüşüm süreci olarak tanımlamıştır. Önceki sanayi devrimleri ile karşılaştırıldığında bu yeni dönüşümün sahip olduğu gelişim ve değişim hızının kat ve kat fazla olduğunu ve bu dönüşüm sürecinin getirdiği genişlik ve derinliğin tüm üretim ve yönetim sistemlerinde yaşanacak olan dönüşümlerin habercisi olduğunu belirtmiştir. Ayrıca daha önce eşi görülmemiş bir işlem gücü ve depolama kapasitesi ile bilgiye erişim noktasında sunduğu olanakların sınırsız olduğunu ve bu olanakların yapay zekâ, robotik, otonom araç ve gereçler, üç boyutlu baskı makineleri, nanoteknoloji, biyoteknoloji, 
malzeme bilimi, enerji ve kuantum gibi alanların ilerleme ve atılım sürecinde çok önemli bir noktada olduğunu ifade etmiştir.

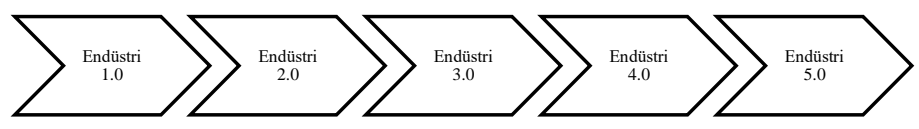

Şekil 1. Endüstri Devrimi Süreci

Genel olarak değerlendirildiğinde Şekil 1'de de görüleceği üzere, endüstri veya diğer bir adıyla sanayi içinde bulunduğumuz dönem itibariyle tarihsel süreç içerisinde beş farklı dönemde ele alınabilir. Su ve buhar gücünün üretimde kullanılmasıyla devam eden üretim faaliyetleri Endüstri 1.0 dönemi ile nitelendirilmektedir. Daha sonra elektriğin keşfi ve seri üretimlerin başlaması Endüstri 2.0 dönemi kapsamında ele alınır. Teknolojide yaşanan gelişmeler ve bu geliş̧melerin insan yaşamına etkilerinin de artmasıyla birlikte dijital ve teknolojik bir takım ürün ve hizmetler ortaya çıkmıştır. Bu gelişim de Endüstri 3.0 döneminde ele alınmaktadır. Endüstri 4.0 ise mevcut teknolojik gelişmelerin ve faaliyetlerin de bir adım öteye taşındığı, nesnelerin interneti, bulut teknolojisi, yapay zeka gibi bilişim hizmetlerinin kullanımını kapsayan endüstri devrimi olarak ifade edilmektedir. Son olarak ise henüz yeni bir kavram olan ve teknolojinin bir tehdit unsuru olarak değil de insan yaşamı için yardımcı bir unsur olduğunu savunan Endüstri 5.0 gündemimizde yer almaktadır. Bu endüstri devrimi aynı zaman da Toplum 5.0 olarak da adlandırılmaktadır.

\section{Endüstri Devrimlerinin Mimarlık Alanındaki Etkileri}

Mimaride kullanılan teknikler hem coğrafi koşulların değiş̧imi hem de kullanıcı ihtiyaçlarının farklılaşmasıyla tarih boyunca sürekli değişim göstermiştir. Endüstrileşme ile yaşanan teknik gelişmeler mimari alanında yeni malzeme ve tekniklerin kullanılmasını sağlamıştır. Sanayi devrimi ile birlikte mimari mevcut kimliğinden çıkıp yepyeni bir kimlik arayışına girmiştir. $\mathrm{Bu}$ süreçte geleneksel mimarlık kavramları tekrar ele alınmıştır. $\mathrm{Bu}$ gelişim ve değişim süreci teknolojik gelişmelerin hızına paralel olarak ilerlemeye devam etmektedir.

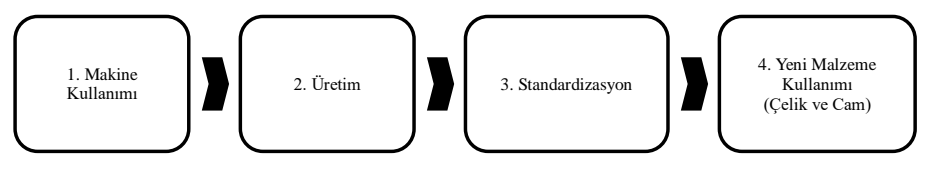

\section{Şekil 2. Endüstri Devriminin Mimari Üzerindeki Etkileri}

18. yüzyllda İngiltere'de sanayi devrimi ile başlayan süreç insanlık tarihinde olduğu gibi mimarlık tarihi açısından da büyük değişimlerin başlangıç noktası olmuştur. Literatürde Endüstri 1.0 'dan önce çoğunlukla halkın tarım ve hayvancilıkla uğraştı̆̆ köy yerleşimleri bulunmaktaydı. Endüstri 1.0 ile birlikte şehirler önemi artmaya başladı ve şehirler hızlı bir gelişim sürecine girdi. $\mathrm{Bu}$ süreçte ulaşım alanında yaşanan gelişmeler de şehir yerleşimlerinin şekillenmesinde doğrudan etkili olmuştur. Ancak mimariyi derinden etkileyen gelişim demirin bir yapı malzemesi olarak kullanılmasıyla farklı özelliklerde yapıların inşasına olanak sağlanması olmuştur. Ayrıca insanların mimariye olan yaklaşımları da değişim göstermeye başlamış ve insanların gösterişli yapılara olan bakış açısı da değişmiştir. İnsanlar Gotik yapılardan daha çok endüstriyel tipte yapılar tasarlamaya başlamışlardır. Gotik yapıların yalnızca insanları etkilemek için tasarlandığı bu dönem artık sona ermiş yepyeni bir bakış açısı ortaya çıkmıştı. Böylece gösterişten uzak fonksiyon olarak daha etkin olan basit yapı tasarımları başlamıştır. Sanayi devrimi mimariyi derinden etkileyerek artık süslü mimariye gerek olmadığını düşünmektedir. İnsanlar Gotik yapılardan daha çok endüstriyel tipte tasarım yapmaya başlamıştı. $\mathrm{Bu}$ dönemde ortaya çıkan hafiflik ve saydamlık kavramları mimari anlamda çeşitlenmede etkili olmuştur. O dönemde bazı mimarlar zaten endüstriyel bakış açısının taraftarıydı ve basit yapı tasarımında oldukça istekli olmuşlardır. Mimarlar endüstriyel gelişmelerle birlikte yapıları tasarlamak için birçok seçeneğe sahip olmaya başlamışlardı. Bu dönem aynı zamanda modern mimarinin de başlangıcı olarak adlandırılmıştır. Fakat zamanla bazı tasarımcılar eski mimari üsluba geri dönme isteği ile farklı çalışmalar yaparak yeni teknoloji ile eski tasarım öğelerini birleştirmeyi denemişler ve ardından Gotik canlanma ve Art Nouveau gibi akımlar ortaya çıkmıştır.

Yap1 endüstrisi 1890'dan sonra hızla değişim göstermiştir. Araba, kamyon, traktör, tank, uçak gibi taşıtların üretiminin yapıldığı ikinci sanayi devriminin çıktıları mimari bilgiyi ve yeni mimari üretim süreçlerini ortaya çıkarmıştır. Endüstriyel yapı inşasının çarpıcı örnekleri bu dönemde ortaya çıkmaya başlamıştır. Hatta mimar Albert Kahn da (1869-1942) bu endüstrileşmeyi en iyi sembolize eden mimarlardan biri olmuştur (Zimmerman, 2017). Son teknoloji mekanik sistemlerin basit ama ustaca yapılandırılmış tasarımlarla birleştiği Kahn için yapılardaki enerji dağıtımı önemliydi. Endüstri 2.0'ın üretime olan etkisi Kahn'ın tasarladığ 1 yapılarda açıkça ortaya konmuştur. Malzeme üretimi alanında ortaya çıkan hızlı gelişim ve değişim süreci uygulama tekniklerini de geliştirmiştir. Kahn'ın eklektik mimari kaplamaların modern teknolojiyle radikal birleşimi Detroit'teki Woodward Caddesi'ndeki Beth El Tapınağı (1922) yapısında açık bir şekilde görülmektedir. Bununla birlikte uluslararası üslupta olan evrenselleşme isteğinin 19. yüzyılın eklektik üslubuna tepki veren modern mimarların, bu tepkilerinden dolayı geleneksel olandan yararlanamamalarından kaynaklandığını savunmaktadır. $\mathrm{Bu}$ yüzden mimarlar, gelenekten endüstri devrimine geçişi sağlıklı bir şekilde yapamamış hem çağdaş hem geleneksel olmayı başaramamışlardır (Özer, 2018).

Büyük Durgunluk, bazı açılardan ikinci sanayi devriminin sonunun ve ekonomist Jeremy Rifkin'in aynı başlıklı kitabında üçüncü sanayi devrimi olarak adlandırdığı dönüşümün başlangıcının sinyalini vermiştir. Bu tür krizlerden büyük zarar gören ve toparlanma süreci çokta hızlı olmayan mimarlık mesleği için sanayi devrimleri önemli başlangıçlara ve sıçramalara olanak sağlamaktadır. Sanayi devrimleri hemen hemen her şeyin yeniden tasarlanmasını gerektirirken mimarlığın gelişiminin sağlanması için bu süreçlerde eski uygulamalara saplanıp kalmak yerine yeni teknolojilerin yarattığı çok ç̧eşitli tasarım firsatlarının değerlendirilmesi gerektirmektedir.

Üçüncü sanayi devriminin önceki iki sanayi devrimi gibi yeni yapı türlerinin gelişimine büyük katkı sağladığı bilinmektedir. 20. yüzyılda şehirler tek kullanımlık bölgelere ayrılmış ve özel kullanım alanlarıyla dolu tekil amaçlar için 
birçok yapı inşa edilmiştir. $\mathrm{Bu}$, ayrıştırma ve uzmanlaşmaya dayalı eski ekonomilerde mantıklı olsa da yeni ekonomide yaşama, çalışma ve yapma arasındaki akışkanlıkla karakterize edilen- amaca yönelik yapıların hızla modası geçeceği tahmin edilmekteydi. Bu dönemde yapılan yapıların yüksek tavanlı, ağır inşaatlı ve insanların kendi alanlarını kitlesel olarak kişiselleştirmelerine izin veren açık planlı, değiştirilebilir bir karaktere sahip olduğu görülmektedir.

Sanayi devrimlerinin teknolojik gelişmelere dayalı sosyal ve ekonomik yapıları etkileyen paradigma değişimleri ile insanlık tarihine damgasını vurduğu söylenebilir. Günümüzde algımızda ve dünya ile etkileşimlerimizde benzer radikal değişikliklerin yaşandığı görülmektedir. $\mathrm{Bu}$ süreç Endüstri 4.0 olarak adlandırılmaktadır. 20. yüzyılın sonunda ve internet ve telekomünikasyon sistemleri tarafindan yönlendirilen fiziksel, dijital, biyolojik ve tasarım alemlerinden emsalsiz bir "teknoloji birleşimi” önceki paradigmaları alt üst etmiştir. Dördüncü sanayi devrimi, teknolojinin tüm bilgi alanlarını etkileyen "boyut, hız ve kapsam" olarak kullanımını genişletmektedir. Endüstri 4.0'un tasarım ve mimaride eklemeli imalat, sanal ve artırılmış gerçeklikler, inşaat robotiği, fiziksel hesaplama, makine öğrenimi, yapay zeka ve sürdürülebilir parametrik analiz dahil olmak üzere hesaplamalı tasarım gibi alanlarda tasarım düşüncesi sınırlarının genişlemesini ve tasarım yöntemlerimiz gelişmesini sağlamaktadır (Henriques, Sousa, Gomez-Zamora, vd, 2020).

Bir zaman çizelgesinde sanayi devrimlerine geniş bir çerçeveden bakıldığında bu devrimlerin teknolojinin büyümesiyle bağlantılı olarak katlanarak daha hızlı gerçekleştiği görülmektedir. İlki 18. yüzyılda, ikincisi ise neredeyse iki yüzyıl sonra meydana gelmiştir. Üçüncüsü yarım yüzyıl sonra, dördüncüsü otuz yıl sonrasında ortaya çıkmıştır. Su ve buhar gücü birinci devrimin ikinci dalgasına, yani mekanizasyon dönemine öncülük etmiştir. Sosyal değişimler şehirleri temelden dönüştürmüştür ve çelik, cam gibi malzemelerle birlikte yeni yapı tasarım tipolojilerinin ortaya çıkmasını teşvik etmiştir (Schwab, 2017). Elektrik ve mühendislik, 19. yüzyılda ikinci devrimini işaret edererek, seri üretim sistemlerinin doğuşunu tetikleyerek, inşaat sektörünün çekirdeğini etkileyerek modern hareketin doğuşuna ilham vermiştir. Bazıları mimarlar için standardizasyon, sanat ve zanaatın düşmanı olarak görünürken, diğerleri için yüksek kalite standartları ve ekonomik verimlilikle yeni inşaat tarzlarının kontrolünü sağlayan yeni tasarım gündemlerini benimsemek için bir firsat olarak görülmüştür. Daha yakın zamanlarda elektroniklerin otomatik üretiminin yanı sıra bilgi ve iletişim teknolojileri, üçüncü sanayi devrimi teşvik etmiştir. Mimarlık bu süreçte geride kalan disiplinlerden biri olmamıştır. Dijital tasarım paradigmasının ilerleyen genişlemesi, geleneksel temsil araçlarını etkilemeye başlayan, daha yüksek derecede tasarım özgürlüğü, karmaşıklığı ve özelleştirmeyi keşfeden analiz ve üretim süreçlerini etkilemiştir.

İnsan hayatına girmiş makinelerin artık hayatın parçası olduğu bir gerçektir. Makineleşme sürecinin takip eden dönemlerde otonom sistemlerin geliştirilmesi ve artık insan gücüne ihtiyaç duymadan üretim yapabilen sistemlerin geliştirildiği dönem olmuştur.

\section{Endüstri 5.0 Nedir?}

Birinci sanayi devrimi, üretimi makineleştirmek için su ve buhar gücünü kullanmıştır. Bilgi birikiminin artması ve yaşanan e-ISSN: 2148-2683 gelişmeler tüm disiplinleri büyük ölçüde etkilerken, dünya nüfusunda dolayısıyla da tüketim hacminde artışlar meydana gelmiştir. Tüketimin artması ile birlikte doğal olarak tüketimi karşılayacak bir üretim hacmine ihtiyaç duyulur. İkinci sanayi devriminde ihtiyaçlara daha çabuk cevap verebilmek ve üretim maliyetlerini düşürebilmek adına elektriğin keşfi ile birlikte mevcut standardı bir adım daha ileriye taşıyacak olan seri üretim yöntemi kullanılmıştır. Üçüncü sanayi devrimine baktığımızda su, buhar ve elektrik gibi kaynaklardan yararlanılarak yapılan üretim sürecine elektronik ve bilgi teknolojilerinde yaşanan gelişmeler dahil olmuştur. Bu gelişmeler çoğu sektör ve alandaki üretim süreçlerini otomatik hale getirmiştir. Ancak tabii ki bu süreçte insan müdahalesini yok saymak olanaksızdır. Çünkü Endüstri 3.0, insan odaklı yapılan üretim sürecine bilgisayarların uyum sağlama sürecidir. Ancak dördüncü sanayi devrimine geldiğimizde, robotların üretimi devralması, üç boyutlu yazıcıların kullanım alanlarının artması, yapay zeka uygulamalarının çoğalması gibi bundan yıllarca önce tahmin dahi edilemeyecek gelişmelerin yaşanması hem günümüz hem gelecek adına umut vaat ederken diğer taraftan da gündemde insanların iş hayatındaki istihdamına karşı bir tehlike unsuru olarak değerlendirilebileceğine ilişkin eleştiriler bulunmaktadır.

Endüstri 4.0 kavramının Nisan 2013'te Almanya'nın Hannover kentinde her yıl gerçekleştirilen CeBIT isimli expo ve teknoloji fuarında tanıtılması ile siber fiziksel sistemlerinin önemi tekrar vurgulanmıştır. Elbette bu yeni dönüşümün getirdiği yenilikler ve sağlamış olduğu faydaları görmezden gelmek imkansızdır. Ancak bununla birlikte ilerleyen süreçte söz konusu eleştiriler zamanla artış göstermiştir. 2017 yılında gerçekleştirilen fuarda dönemin Japonya Başbakanı Shinzo Abe, teknolojinin toplumlar için bir tehdit unsuru olarak değil, bir yardımcı unsur olarak düşünülmesi gerektiği felsefesine dayanan Endüstri 5.0'1 diğer bir ifade ile Toplum 5.0'1 tanıtmıştır.

Aslında Toplum 5.0 bu tanitımdan daha önce Aralık 2015'te Japonya'nın 5. Bilim ve Teknoloji Temel Planı'nda temel bir kavram olarak tanımlanmıştır. Bu planda siber alan ile gerçek dünyanın tam anlamıyla entegre olduğu, gelecekteki toplumun sahip olacağı ideal formun "Süper Akıllı Toplum" olarak nitelendirilmesi olarak ifade edilmektedir. Bu nitelik ise ürün ve hizmetlere ihtiyaç duyanların, ihtiyaç duydukları miktar ve zamanda ulaştırılmasını kapsamaktadır. Ayrıca sistem yaş, cinsiyet, bölge gibi çeşitli faktörleri dikkate alarak bütün toplumların yüksek hizmet kalitesine erişmesi için çalışmaktadır (Celep, 2020).

Özdemir ve Hekim'e göre (2018) Endüstri 5.0, kavram ve uygulamalar açısından Endüstri 4.0 dayanmaktadır. Sahip olduğu bilgi hazinesini günden güne artıran ve ilerleten bir konsepttir. Nahavandi (2019) Endüstri 4.0'ın verimliliği arttırmak adına üretim süreçlerini otomatikleştiren bir süreç olduğunu ancak bu sürecin de insan olgusunu göz ardı ettiğini belirtmiştir. $\mathrm{Bu}$ durumun, sürecin de yaygınlaşmasıyla birlikte Endüstri 4.0'ın en büyük problemi olacağını, dahası problemin de büyümesiyle istihdam konusunda sendika ve politikacilardan baskı göreceğini ifade etmiştir. Tam da bu noktada Endüstri 5.0'1 bir çözüm yolu olarak düşünülebileceğini belirtmiştir. Pathak'a göre (2020) ise Endüstri 5.0, insanlarla makineler arasındaki etkileşimi vurgulayan ve daha çok insan ve makine ara yüzlerine odaklanan bir dönüşümdür.

Endüstri 5.0 merkezinde insan olan, sanal alan ile fiziksel alan arasında gelişmiş ve güçlü bir bağlantı kuran yeni bir bakış 
açısıdır. İnsanların bu yeni dönüşüm sürecinde şu ana kadar yaptıkları işlerde artık birer temsilci veya aracı görevi üstlenmesini ve bu konuda desteklenmesini içermektedir. Endüstri 5.0 ile birlikte önemi günden güne artan ve gelişmesinde ciddi katkılarının olduğu teknolojiler aşağıda yer almaktadir (BTK, 2020).

\section{- Nesnelerin İnterneti:}

Nesnelerin internetini (Internet of Things) akıllı bir iletişim ağ1 olarak tanımlamak mümkündür. Nesnelerin internetinin kısaltmas1 literatürde "IoT" olarak kullanılmaktadır. Veri alışverişi, diğer cihaz ve sistemler arasındaki bağlantı ve fiziksel nesnelerin dahil olduğu bu ağ, toplanan sensör verilerini ağ geçidine, buluta veya başka bir uç cihazla paylaşır. Diğer cihazlar da bu ağdan aldıkları bilgi ve komutlara göre hareket ederler.

\section{- Büyük Veri:}

Uluslararası literatürde "Big Data" olarak geçen büyük veriler, Iot teknolojisinin gelişimi ve bu teknolojiye gösterilen ilginin artması ile birlikte daha çok gündemde yer almaya başlamıştır. Yalnızca belirli alanlarda değil bugün yaşamımızda bulunan her alanda büyük veriler yer almaktadır. Tüm alanların bu verileri doğru zamanda, ihtiyaçlara uygun bir şekilde kullanması tüm toplumlar için çok önemlidir. Çünkü toplumlar artık bilgi toplumları ve süper akıllı toplumlar olarak kabul edilmektedir. $\mathrm{Bu}$ doğrultuda da toplumların yaşam ve çalışma biçimleri büyük oranda etkilenmektedir. $\mathrm{Bu}$ verilerin analiz edilmesi ve elde edilen bulgular dahilinde doğru çıkarımların yapılabilmesi, yaşamı kolaylaştırıcı uygulamalar geliştirme noktasında önemli bir yer tutmaktadır.

\section{- Yapay Zekâ:}

Yapay zekâ (Artificial Intelligence), tanımlanan görev ve sorumlulukları yerine getirebilmek adına insan zekasını taklit eden, topladıkları veriler sayesinde kendisini geliştirebilen sistem veya makineler olarak tanımlanmaktadır. Bu sistem veya makineler, görev ve sorumlulukları yerine getirmek için büyük verileri işler. Ekonomi, sağlık, eğlence, güvenlik, turizm, mühendislik, mimarlık gibi çeşitli alanlarda yapay zeka kullanımın her geçen gün artması hem tüketici tarafında müşteri memnuniyetinin artması hem de üretici tarafında zaman, mekan ve şekil faydası sağlaması için yarar sağlamaktadır.

\section{- Robotik:}

Robotik, robotların tasarımını, inşasını, işletilmesini ve kullanımını içeren bir teknoloji olarak tanımlanmaktadır. Amacı, insanlara günlük yaşamlarında yardımcı olabilecek akıllı makineler tasarlamak ve uygulama noktasında işlerlik kazandırmaktır. Tehlikeli koşullar altında yapılan tüm işler için veya üretim açısından değerlendirildiğinde ise maliyetleri azaltmak ve üretimdeki verimi daha yüksek seviyelere çıkarabilmek için her geçen gün geliştirilmektedir.

\section{- Kablosuz Sensör A $\breve{g ̆}$ :}

Kablosuz sensör ağı, çevrenin fiziksel koşullarını izlemek ve kaydetmek ve toplanan verileri merkezi bir konumda düzenlemek için mekansal olarak dağılmış sensör grubu olarak tanımlanmaktadır. Sicaklık, ses, kirlilik seviyeleri, nem, rüzgâr vb. gibi çevresel koşulların ölçülmesini sağlamaktadır. Bu teknolojinin gelişmesi, insanları işleri yapan değil işleri kontrol eden birer temsilci olmalarını sağlamıştır. Bu teknolojilerin kullanılmasıyla birlikte çeşitli alanlarda inovatif girişimler ile yeni öneri ve çözümler getirilmiştir.

Her endüstri devrimi bir dönüşüm sürecidir ve bu süreçler de içerisinde hareket ettirici bir güç barındırmaktadır. Bununla birlikte sürecin getirdiği birtakım gelişmeler ve bu gelişmeler karşısında da toplum tarafında birtakım endişeler bulunmaktadır. Endüstri 1.0'dan Endüstri 5.0'a kadar olan tarihsel serüvende, dönüşüm süreçlerinin bünyesindeki itici güçler, gelişime konu olan yenilikler ve toplum tarafındaki endişeler yer almaktadır.

\section{Endüstri 5.0 ve Mimarlık}

21. yüzyılın başlangıcında ortaya çıkan teknolojik gelişmeler makinelerin sağladığı olanaklarla birlikte değişim sürecinin farklı bir alana evrilmesine neden olmuştur. Tüm alanlarda olduğu gibi mimaride bu hızlı değişim sürecinden etkilenmiş ve gelişime açık bir alan olduğu için adaptasyon hızı yükselmiştir. Endüstri 5.0 olarak da adlandırılan bu süreçte mimari uygulamaların değişime kolaylıkla uyum sağlamasında yap1 sektörünün dinamik yapısı ve yeni nesil mimarların teknolojiye yakın aynı zamanda yatkın olmalarının etkisi büyüktür.

$\mathrm{Bu}$ çalışma da Endüstri 5.0'ın mimariye olan etkisi önceki bölümde açıklanan büyük veri, nesnelerin interneti, yapay zekâ, robotik ve kablosuz sensör ağı üzerinden değerlendirilmiştir.

"Büyük Veri” olarak adlandırılan ve değişim sürecini yönlendirmede ana etken olarak bilinen bilgi kaynaklarının tamamıdır. Mimarlık alanında veri toplama kavramının kullanılması çok eski zamanlara dayanır. En önemlilerinden biri olan "Kullanıcı ihtiyaçlarının belirlenmesi" konusu da mimari gelişimin temelini oluşturur. Mimarlık, barınma için barınaklara olan ihtiyaçların oluşturduğu ve ilk andan başlayarak günümüze kadar ulaşan ve değişen konfor ihtiyaçlarına cevap aramaktadır. Kullanıcı ihtiyaçların belirlenmesi ve bu verilerin toplanarak değerlendirilmesi Endüstri 5.0 içerisinde yer alan büyük veri kavramı altında değerlendirilebilir.

Örneğin son yıllarda oldukça etkili bir yaklaşım olan “sürdürülebilir mimarlık" büyük veri kavramı altında iklim verilerinin toplanması ve değerlendirilmesi sonrasında ortaya çıkan vahim sonucun bir ürünüdür. Yine aynı kavramı etkileyen enerji kaynaklarının tükenmesi ve yenilenebilir enerji kaynaklarının potansiyelinin belirlenmesi de büyük veri kavramı altında değerlendirilmektedir. $\mathrm{Bu}$ ve bunun gibi farklı örnekleri vermek mümkündür. Mimariyi gerek kavramsal gerekse teknik olarak etkileyen verilerin hızla, doğru bir şekilde toplanıp değerlendirilmesini kapsayan "Büyük Veri" kavrama ileride de sıkça başvurulacağı ve bu kavramın gelecekte çok farklı yaklaşımların ortaya çıkmasına olanak sağlayacağı düşünülmektedir.

Nesnelerin İnterneti (IoT) olarak adlandırılan uzaktan erişim ile yönetilebilen teknolojiler ve bu teknolojiler yapıların geleceğini şekillendirmektedir. Son zamanlarda geleneksel yapıları akıllı, verimli ve güvenli yapılara dönüştürmek için çeşitli uygulama ve ortamlarda IoT kullanılabilmektedir. Yapılar için çalışmalar, iç ortam otomasyonu, akıllı enerji yönetim sistemleri ve sağlık tesisleri olmak üzere üç ana kategoriye ayrılarak değerlendirilmektedir. 
Önde gelen bir ileri teknoloji olan Nesnelerin İnterneti'ni (IoT) kullanan yapılarda otomasyon, güvenlik ve emniyeti artırmak, cihazların/sistemlerin uzaktan kontrolünü sağlamak, yap1 sakinlerini izlemek, verimliliği artırmak, görselliği iyileştirmek ve termal konfor için son teknolojik çözümler sunabilmektedir (Akkaya, Guvenc, Aygun, vd, 2015). IoT'nin heterojen cihazlara bağlanabilme, bilgileri yönetebilme ve değiş tokuş edebilme, konumları doğru bir şekilde takip edebilme, enerji kullanımını optimize edebilme ve özellikle kablosuz iletişim teknolojileri aracıllğıyla mahremiyet ve güvenliği koruma gibi avantajları bulunabilmektedir. (Shouran, Ashari \& Priyambodo, 2019).

Bir yapıyı inşa etmek, çok fazla ön planlama gerektiren ve çok zaman alan bir süreçtir. Bu süreçte öncelikle tasarımı gerçekleştiren mimarın, birtakım araştırmalar yapması ve gerek duyduğu verileri elde etmek için çok uzun ofis saatlerinde çalışması gerekmektedir. Ancak bu ön planlama bazen kısıtlı zamandan dolayı yeterli olmamaktadır. Yapay Zekâ, tüm verileri analiz ederek ve mimarın çok fazla zaman ve enerji tasarrufu sağlayabilecek modeller oluşturarak bir mimarın işini önemli ölçüde kolaylaştırmasını sağlayabilmektedir. Örneğin parametrik mimari, bir mimarın çeşitli çıktı tasarımları oluşturmak için belirli parametreleri değiştirmesine ve daha önce hayal bile edilemeyen bu tür yapılar oluşturmasına izin veren bir alan olarak adlandırılmakta ve bir mimarın programlama dili olarak düşünülebilmektedir. Mimarın bir yapıyı düşünmesine ve onu diğer bazı gereksinimlere uyacak şekilde yeniden çerçevelendirmesine olanak tanımaktadır. Bunun gibi bir süreçte, Yapay Zekâ mimarın çabasını azaltmasına ve böylece mimarın farklı fikirler hakkında özgürce düşünebilmesine ve yeni bir şey yaratabilmesine olanak tanır. Bunun gibi mimarinin pek çok alanında yapay zekâ kullanılabilmektedir (As, Pal \& Basu, 2018).

Son y1llardaki teknolojik ve kavramsal gelişmeler, robotik yapının prototip olarak uygulanmasını sağlamıştır. Bu bağlamda robotik yapı, hem fiziksel olarak inşa edilmiş robotik ortamları hem de robotik olarak desteklenen yapı süreçlerini ifade etmektedir. Yapıların kullanıcıları ve çevreleriyle gerçek zamanlı olarak etkileşime girmesini sağlayan mekatronik cihazları içeren yeniden yapılandırılabilir, robotik ortamlar fiziksel veya duyusal değişim ve varyasyon yoluyla yoğun zaman dilimlerinde ve adreslerde birden çok değişen işleve izin vermektedir. (Bier \& Knight, 2010).

Genel anlamda, mimaride gömülü robotik uygulamalar, (a) sağlık, demografik değişim ve esenliğin yanı sıra (b) sürdürülebilir iklim kontrolü ve enerji üretimi ile ilgili alanlarda tanımlanmıştır. $\mathrm{Bu}$ alanların her biri için robotik aşağıdaki şekilde kullanılabilir:

Robotik yapı bileşenleri (kapılar, duvarlar, zeminler vb.), hızlı nüfus artışı ve kentsel yoğunlaşmanın yanı sıra, inşa edilen alanın çağdaş verimsiz kullanımı (\%25) ile başa çıkmak için çözümler sunan günlük yaşam aktivitelerini destekleyebilir. Ayrıca, yapı bileşenlerinde gömülü robotik sağlık hizmetlerine ve iyileşmeye yardımcı olabilirken, fiziksel, bilişsel, zihinsel, duyusal, duygusal, gelişimsel veya bu bozuklukların bazı kombinasyonları azaltılabilir veya uzamsal duyarlılık yoluyla en aza indirilebilir (Smith, 1996).

Yap1 uygulamaları kapsamında kablosuz sensör ağ1 teknolojisi çok yeni bir teknolojidir ve gelecekteki mimari e-ISSN : 2148-2683 gelişimin temelleri bu sistemlere bağlı olacaktır. Kablosuz sensör ağları, koşullar ve ekipman hakkındaki verileri daha kolay erişilebilir hale getirerek yapılarda enerji tasarrufu ve kullanıcıların konforunun iyileştirilmesi için muazzam firsatlar sunar. Akıllı yapılar olarak adlandırılan sistemler kapsamında artık kendi kendini yöneten değiştiren zamanla geliştiren otomasyon sistemleriyle donatılabilecektir (Pautasso, Zimmermann \& Leymann, 2008). Bununla birlikte günümüzde kablosuz sensör ağı teknolojisi yapının enerji yönetimi, kaynak tüketiminden kullanıcı sürecindeki ihtiyaçlarının karşılanmasına kadar pek çok alanda etkin şekilde uygulanmaktadır.

Kablosuz iletişim teknolojisi, sensörlerin, aktüatörlerin ve kontrolörlerin kurulumunu kolaylaştırarak yapı içindeki koşulları izlemek ve kontrol etmek için zengin firsatlar sunmaktadır. Yapı otomasyon sistemleri şu anda 1sıtma, havalandırma ve iklimlendirme (HVAC) ve aydınlatma sistemlerini verimli bir şekilde çalıştırılırken, bir yapı genelinde daha fazla sensör ve aktüatörün bulunması, enerji tüketimini azaltırken yap1 sakinlerinin konforunu daha da iyileştirebilir. Ek olarak, ekstra sensörler bir yapıdaki güvenlik ve güvenlik sistemlerini güçlendirebilir (Kintner-Meyer \& Brambley, 2002). Kablosuz teknoloji, kurulum maliyetini ve çabasını önemli ölçüde azaltarak bir yapıda daha fazla sayıda sensör, aktüatör ve kontrolör sağlamaktadır. Sinyal kablosunun ortadan kaldırılması, uyarlanabilir konfigürasyonlarla mekanlarda daha fazla esneklik sağlar ve yapıya zarar vermeden tarihi yapılarda algılama ve kontrole izin verebilmektedir.

\section{Sonuç}

Geçmişten günümüze tüm insanlar, içinde bulundukları dönemin şartlarına göre birincil ve ikincil ihtiyaçlarını gidererek bir yaşam sürmeye çalışmıştır. İnsanların çalışıkları her sektör veya ilgilendikleri her alan, kendi zorluklarına ve kendi içerisinde çözülmesi gereken birtakım problemlere sahiptir. Tam da bu noktada gelişim ve değişim olgusu bir çözüm olarak göze çarpmaktadır. Değişim ve gelişimin temelinde ihtiyaçların tam olarak giderilememesi veya giderildiklerinde kısmi memnuniyete sahip olunması yatmaktadır. Böylelikle her alan tarihsel süreç içerisinde kendini geliştirmiş ve ihtiyaçlara cevap vermeye çalışmıştır.

Endüstri devrimleri de yalnızca endüstri alanında başlayan bir dönüşüm süreci değildir. Çeşitli alanlarda da bir dönüşüm süreci başlatmıştır. Sosyal bilimlerden fen bilimlerine, sağlık bilimlerinden spor bilimlerine kadar her alanda bilgi birimleri zamanla çoğalmıştır. Bu süreçlerde insanların yaşam biçimleri, beğenileri, talepleri, alışkanlıkları ve çalışma standartları da farklılaşmıştır.

$\mathrm{Bu}$ alanlar arasında Mimarlık, yapı inşası bakımından Endüstri 5.0 yepyeni bir bakış açısı ortaya koymuş ve hem toplumsal ihtiyaçların değişimine hem de yapım tekniklerinin güncellemesinde öncü olmuştur. Endüstri 5.0 mimariyi mimarlık eğitiminden malzeme seçimine ve enerji tüketimi kontrolüne kadar sayısız alanda değişime yönlendirmiştir.

İşlev, mimari tasarımda her zaman önemli bir itici güç olmuştur, yani doğrudan amaç ve faydadan biçim üretme niyeti. 1896'da Louis Sullivan, "biçim işlevi izler" ve bir yapının güzelliğinin, önceden tasarlanmış biçimlerden veya yapılı mirasa yapılan referanslardan değil, doğrudan işlevin pratik ve etkili bileşiminden kaynaklandığını savunmuştur. Endüstri devrimleri 
ile birlikle hızla değişen kullanıcı ihtiyaçları ve mekân ihtiyacını doğuran fonksiyon çeşitleri değişmiştir. Bu süreçte fabrikaların kurulumu, üretimin tesislerini inşası, gibi yeni yapı tiplerinin oluşumu aynı zamanda da malzeme teknolojisinin hızlı gelişim mimari alanında önemli sıçramaların yaşanmasını sağlamıştır. Bu süreçte kullanıcı profili değişmeye başlamış yep yeni ihtiyaçların ortaya çıkmıştır. Fonksiyonun kullanımına uygun tasarım yapmak ve kullanıcıların ihtiyaçlarına cevap veren yapılar inşa etmek elbette ki mimarın temel amaçlarından biridir.

Gelişen ve değişen teknolojiye hızla ayak uyduran bir kullanıcı kitlesi tabi ki teknolojinin tüm imkanlarını yaşadığı mekânda talep edebilir. Endüstri 5.0 ile ortaya çıkan yeni sistemlerin yapı sektörü üzerindeki etkisi yadsınamaz. Büyük veri, nesnelerin interneti, yapay zekâ, robotik ve kablosuz sensör ağı sistemleri gelecekte yapıların tasarımında öncülük edeceği ve mimari üretim de temelden değiştireceği öngörülmektedir. Büyük veri sistemleri kullanılarak dünyadaki mimari veriler analiz edilerek istenilen mimari özellikte yapı oluşturmak eskisi kadar uzun sürmeyecektir. Yapay zekâ teknolojisinden yararlanılarak çizim programların geliştirileceği ve şu an aktif olarak kullanılan programların yerini alacağı düşünülmektedir. Akıllı yapılar kavramı gelişerek kullanıcının ihtiyaçlarını önceden belirleyebilen sistemler geliştirilmektedir. Buda kullanıcılar hangi fonksiyona sahip alanda olursa olsun ihtiyaç duyduğu konfor koşullarına ulaşabilecektir. Otomasyon sistemleri kullanılarak enerji tasarrufu ve yapı güvenlik sağlanmaktadır.

$\mathrm{Bu}$ çalışmada yeni nesil yapı anlayışının teknoloji 1şığında hızla değişen konfor koşullarını sağlamak üzerine ilerlediği ve mimari alanda yapılan çalışmaların bu yönde çok önemli gelişmelere açık olduğu tespit edilmiştir. Endüstriyel devrimleri mimarlık disiplini üzerinde doğrudan etkili olmuştur ve bununla birlikte mimarlık mesleğinde yeni uzmanlaşma alanlarının ortaya çıkmasını sağlamıştır. Hiç şüphesiz gelecekte de bu süreç devam edecektir.

\section{Kaynakça}

Akkaya, K., Guvenc, I., Aygun, R., Pala, N. \& Kadri, A. (2015). IoT-based Occupancy Monitoring Techniques for Energyefficient Smart Buildings, in: 2015 IEEE Wirel. Commun. Netw. Conf. Workshop WCNCW, 58-63.

Allen, R. C. (2009). The British Industrial Revolution in Global Perspective. Cambridge University Press.

As, I., Pal, S., \& Basu, P. (2018). Artificial Intelligence in Architecture: Generating Conceptual Design via Deep Learning. International Journal of Architectural Computing, 16(4), 306-327.

Bier, H. \& Knight, T. (Eds.). (2010). Digitally-driven Architecture. In 6th Footprint Issue. Delft: Stichting Footprint.

Canbay, P. \& Demircioğlu, Z. (2021). Endüstri 5.0'a Doğru: Zeki Otonom Sistemlerde Etik ve Ahlaki Sorumluluklar. AJIT-e: Bilişim Teknolojileri Online Dergisi, 12(45), 106123.

Celep, D. N. (2020). Toplum 5.0: İnsan Merkezli Toplum. Türk Eğitim Derneği

Günay, D. (2002). Sanayi ve Sanayi Tarihi. Mimar ve Mühendis Dergisi, 31, 8-14.

Jevons, H. S. (1931). The Second Industrial Revolution. The Economic Journal, 41(161), 1-18.

e-ISSN: 2148-2683
Kintner-Meyer, M. \& Brambley, M. R., (2002). Pros \& Cons of Wireless, ASHRAE Journal, 44(11), 54-61.

Li, W., Logenthiran, T., Phan, V. \& Woo, W. L. Implemented IoT-based Self-learning Home Management System (SHMS) for Singapore, IEEE Internet Things J 5 (2018) 2212-2219.

Nahavandi, S. (2019). Industry 5.0-A Human-centric Solution. Sustainability, 11(16), 4371.

Özdemir, V. \& Hekim, N. (2018). Birth of Industry 5.0: Making Sense of Big Data with Artificial Intelligence, "The Internet of Things" and Next-generation Technology Policy. Omics: A Journal of Integrative Biology, 22(1), 65-76.

Özer B. (2018). Kültür, Sanat, Mimarlık, YEM Yayınları, İstanbul.

Pathak, P., Pal, P. R., Shrivastava, M., \& Ora, P. (2019). Fifth Revolution: Applied AI \& Human Intelligence with Cyber Physical Systems. International Journal of Engineering and Advanced Technology, 8(3), 23-27.

Pautasso, C., Zimmermann, O. \& Leymann, F. (2008), Restful Web Services vs. "Big" Web Services: Making the Right Architectural Decision. In Proc. of the 17th international Conference on World Wide Web (WWW).

Power is Transforming Energy, The Economy, And The World. Macmillan.

Rifkin, J. (2011). The Third Industrial Revolution: How Lateral

Schwab, K. (2017). The Fourth Industrial Revolution. Currency.

Smith, B. L. (2001). The Third Industrial Revolution: Policymaking for the Internet. The Columbia Science and Technology Law Review, 3, 1-45.

Shouran, Z., Ashari, A. \& Priyambodo, T. Internet of Things (IoT) of Smart Home: Privacy and Security, Int. J. Comput. Appl. 182 (2019) 3-8.

Smith, R. O. (1996). Measuring the Outcomes of Assistive Technology: Challenge and Innovation. Assistive Technology, 8, 71-81.

Zhou, K., Liu, T. \& Zhou, L. (2015). Industry 4.0: Towards Future Industrial Opportunities and Challenges. 12th International Conference on Fuzzy Systems and Knowledge Discovery (FSKD), 2147-2152.

Zimmerman, C. (2017). Albert Kahn in the Second Industrial Revolution. AA Files, (75), 28-44. 